\title{
Study on Bioagents/Bioaerosols Standoff Detection by Lidar
}

\author{
Yang Hui ${ }^{1}$, Sun Yanfei ${ }^{1}$, Wang Tiedong ${ }^{1}$, Zhao Xuesong ${ }^{2}$ \\ ${ }^{1}$ New Star Application Technology Institute, Hefei, China \\ ${ }^{2}$ Key Lab. of Environmental Optics \& Technology, CAS, Hefei, China
}

Email address:

sanpedroman@163.com (Yang Hui),hope32@163.com (Sun Yanfei), 18905607537@189.com (Wang Tiedong), xszhao@aiofm.ac.cn (Zhao Xuesong)

\section{To cite this article:}

Yang Hui, Sun Yanfei, Wang Tiedong, Zhao Xuesong. Study on Bioagents/Bioaerosols Standoff Detection by Lidar. International Journal of Environmental Monitoring and Analysis. Vol. 4, No. 2, 2016, pp. 39-44. doi: 10.11648/j.ijema.20160402.11

Received: February 21, 2016; Accepted: March 10, 2016; Published: March 29, 2016

\begin{abstract}
Scattering, fluorescence and polarization are the important data source for bioagent or bioaerosol time-space observation and identification. This paper stated and discussed the theory and data inversion principles for Mie scattering, laser induced fluorescence and polarization sensing Lidar. The sensing and data inversion results for bioagent/bioaerosol extinction coefficient, horizontal linear depolarization ratio were also demonstrated. The signal and $S N R$ simulation of fluorescence lidar were also demonstrated. The sensing results revealed that the three kinds of detecting technology approaches are reasonable and potential for bioagent/bioaerosol characterization and recognition.
\end{abstract}

Keywords: Bioagents/Bioaerosols, Lidar, Laser Induced Fluorescence, Depolarization Ratio, Mie Scattering

\section{Introduction}

Biological warfare agents (BWAs) or bioagents are live pathogenic microorganisms and biotoxin used in biological terrorism attack or in the battlefield, which are capable to cause mass infections or poisoning of people, animals and/or plants at reasonable economical cost. Bioagents can be sorted according to the causal agent as bacteria, viruses, rickettsiae and toxins $[1,2,3]$. Bioagents are relatively inexpensive to produce and can yield a significant impact as a terrorist weapon. Up to now, there are more than 1200 kinds of bioagents that can be produced to biological weapon. The infection of bioagents is mainly caused through absorption from respiratory tract, alimentary tract, or direct contact of skin, the deterrence will be much more awful enhanced by the recombinant DNA technique, and the death rate of unimmunized people will be nearly $100 \%$. The World Health Organization estimated that attacking a large city with $50 \mathrm{~kg}$ of anthrax spores would produce 95,000 deaths and an additional 125,000 sicknesses [4]. And for viral hemorrhagic fevers, less than 10 organisms can cause decease and many of the most dangerous biological warfare agents are infectious when less than 10,000 organisms or spores are inhaled [5].
On the other hand, because of the common intrinsic fluorescence characteristics of fluorophore, such as tryptophan, tyrosine, etc., it's difficult to distinguish harmless bacteria from fatal bacteria, even genetically in some cases. Bioagents can be disseminated through at least three major ways: by vector (i.e., insects), by contaminated water or food supplies, and the most effective way of dispersion is the form of aerosol particles suspending in the air. As for the biological aerosol (bioaerosol), it includes plant and insect debris, fungal and plant spores, pollen, cells, viruses and bacteria. Abundance in the atmosphere, bioaerosol affects the cloud microphysical processes, helps to the biodiversity and disease transmission through long range transport.

Typical point detection and discrimination system based sample technique can detect bioagents/bioaerosols with a low time resolution and a relatively high false alarm rate, the bioactivity can be deteriorated during the sample procedure, and the exterior factors such as dehydration, variation of temperature will also affect the recognition result.

Early warning of a biological attack such as lidar standoff detection offers many potential capabilities not easily provided by point detection systems such as sensitivity over a wide area, easy to deploy, capability of mapping, allowing for early warning to downwind assets and population, etc. 
Assisted by plume modeling technique, mapping and tracking of the hazard cloud by lidar can help to determine origin, evolution of a biological attack, thus guide treatment and decontamination efforts. For example, at a condition of $20 \mathrm{~km} / \mathrm{h}$ wind velocity, the population on the ground can get a early warning time of about 6 minutes if the windward [6]. For these reasons the need to develop methods to remotely detect and discriminate biological aerosols from background aerosols and ultimately to discriminate biological warfare agents from naturally occurring aerosols, is paramount.

Elastic Mie scattering, laser induced fluorescence (LIF) and polarization scattering are three major bioagents/bioaerosols remote sensing techniques. In this paper, the theory, technology, ability of detection and other factors affecting detection are discussed individually.

\section{Principle of Bioagents/Bioaerosols Remote Detection by Lidar}

Bioagents/bioaerosols remote detection is based on the interaction physical process between the laser beam and particles on the path, such as rayleigh scattering, raman scattering, Mie scattering, and the fluorescence process induced by incident ultraviolet laser beam. The fluorophores in the biological material, such as trypophan, tyrosine, Phenylalanine, and NADH (nicotinamide adenine dinucleotide) absorb the incident radiation at a ultraviolet wavelength and re-emit fluorescence at one or more longer wavelengths, and riboflavin absorbs ultraviolet and incident radiation and emits at visible wavelength.

Bioagents/bioaerosols might be non- spherical particle, the backscattering emission is not linear depolarized when illuminated by a polarized light. Through the wave plates and polarization analyzer and double-channel PMT, the received parallel and perpendicular signal can be collected and recorded individually, and finally, the bioagents/bioaerosols can be discriminated with depolarization ratio. Using depolarization ratio database for bioagents/bioaerosols and interferents, the bioagents, such as anthrax, plague, ricin, etc. and bioaerosol, such as dust, smoke, pollen, etc. can be differentiated.

So, Mie scattering lidar is used mainly for searching, positioning and space mapping of the bioagents, fluorescence lidar is used mainly to determine the fluorescence character of bioagents, and polarization lidar can be used to determine the type of bioagents cloud and provide exact early warning.

First, confirm that you have the correct template for your paper size. This template has been tailored for output on the A4 paper size. If you are using US letter-sized paper, please close this file and download the file "MSW_USltr_format".

\subsection{Lidar Configeration}

The overall schematic diagram of lidar is illustrated in Figure 1. The lidar is consisted of laser emitting sub-system, receiving sub-system and data acquisition sub-system. The returned fluorescence signal is rather weak, so the signal can be collected by photon counter, intensified CCD or PMT array. The doubled and tripled output pulse with $30 \mathrm{~mJ}$ energy from a flash-pump Nd:YAG laser was used for Mie scattering, polarization scattering and fluorescence measurements. Beam expanders were employed to obtain outgoing laser beams with a $2-\mathrm{cm}$ diameter and $0.5 \mathrm{mrad}$ divergence $(80 \%$ of the total energy). Linear polarization purity of $1 / 500$ for the laser beam was obtained with a polarization cube. A $300 \mathrm{~mm}$ Cassegrain telescope with an adjustable FOV collects elastically scattered 532nm Mie, $355 \mathrm{~nm}$ parallel and perpendicular power polarization and $355 \mathrm{~nm}$ fluorescence signal. The scattering, polarization and fluorescence signal were accumulated for at least 60 seconds, and raman signal was accumulated for at least 30 minutes.

The main specifications of lidar are summarized in table 1 .

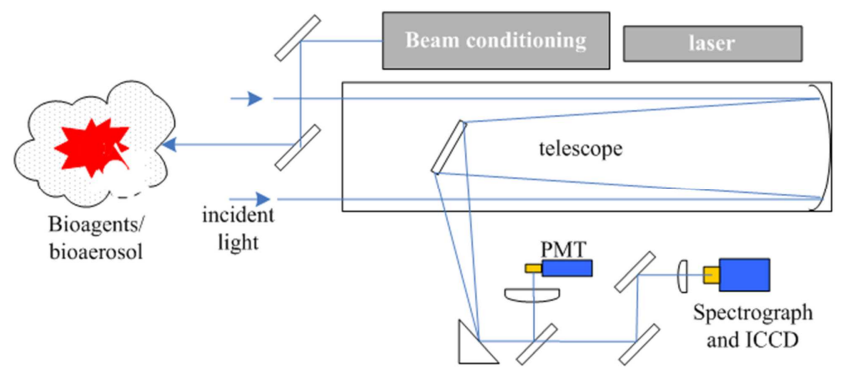

Fig. 1. Sketch of bioagent/bioaerosol sensing lidar.

Table 1. Main specifications of fluorescence sensing lidar.

\begin{tabular}{ll}
\hline Laser & Nd:YAG \\
\hline Wavelength(nm) & $532,355,387$ (Raman) \\
Laser pulse energy $(\mathrm{mJ})$ & $>40$ \\
Repetition rate(Hz) & 20 \\
Pulse width(ns) & 20 \\
Accumulated pulse counts & 2000 \\
Telescope & Schmidt-cassegrainian \\
Diameter(mm) & $\Phi 300$ \\
Field of view(mrad) & $1-2$ adjustable \\
Receiver & \\
Filter central wavelength(nm) & 465 \\
Filter width(nm) & 60 \\
Total optical transmittance & 0.16 \\
PMT quantum yield & 0.2 \\
Range resolution(m) & 15 \\
Fluorescence central wavelength(nm) & 465 \\
NADH Quantum yield & 0.1 \\
NADH fluorescence cross section & $5 \mathrm{e}^{-12}$ \\
\hline
\end{tabular}

\subsection{Theory of Mie Scattering and Fluorescencel Lidar}

The elastic Mie lidar equation assuming single scattering and is describing the received optical power as [7]

$$
\mathrm{P}\left(\lambda_{\mathrm{L}}, \mathrm{z}\right)=\mathrm{P}_{\mathrm{L}} \cdot \frac{\mathrm{A}_{0}}{\mathrm{z}^{2}} \cdot \xi\left(\lambda_{\mathrm{L}}\right) \cdot \beta\left(\lambda_{\mathrm{L}}, \mathrm{z}\right) \cdot \xi(\mathrm{z}) \frac{\mathrm{c} \cdot \tau_{\mathrm{L}}}{2} \cdot \mathrm{T}(\mathrm{z})
$$

where $P_{L}$ is the outgoing effect of the laser and is calculated as $\mathrm{P}_{\mathrm{L}}=\mathrm{E}_{\mathrm{L}} / \tau_{\mathrm{L}}, \mathrm{A}_{0}$ is the aperture area, $\mathrm{z}$ is the range in meter, $\xi\left(\lambda_{L}\right)$ is the optical efficiency of the system, $\beta\left(\lambda_{L}, z\right)$ 
is the volume backscatter coefficient for the elastic backscattering, $\xi(\mathrm{z})$ is the overlap function between the transmitter and the receiver field-of-view. The speed of light is $\mathrm{c}$ and $\tau_{\mathrm{L}}$ is the pulse length of the laser, $\mathrm{T}(\mathrm{z})$ is the total transmission. The laser wavelength is denoted as $\lambda_{L}$. The receiver noise is simulated by the detector and optical background induced noise. The total transmission at range $\mathrm{z}$ is in general calculated as

$$
T(z)=\exp \left[-2 \int_{0}^{z} \alpha\left(\lambda_{L}, z\right) d z\right]
$$

The extinction coefficient $\alpha\left(\lambda_{\mathrm{L}}, \mathrm{z}\right)$ can be divided into two terms, one for the atmospheric background and one for the bioagents/bioaerosol cloud,

$$
\mathrm{P}(\lambda, \mathrm{z})=\mathrm{P}_{\mathrm{L}} \cdot \frac{\mathrm{A}_{0}}{\mathrm{z}^{2}} \cdot \mathrm{K}_{0}\left(\lambda_{\mathrm{L}}\right) \cdot \mathrm{T}(\mathrm{z}) \cdot \xi(\mathrm{z}) \cdot \mathrm{N}(\mathrm{z}) \cdot \frac{\sigma^{\mathrm{F}}\left(\lambda_{\mathrm{L}}\right) \cdot \mathrm{L}^{\mathrm{F}}(\lambda)}{4 \pi} \cdot \frac{\mathrm{c}_{0} \cdot \tau_{\mathrm{L}}}{2}
$$

where $\mathrm{K}_{0}\left(\lambda_{\mathrm{L}}\right)$ is the optical filter function including the optical efficiency, $\mathrm{N}(\mathrm{z})$ is the particle concentration, $\sigma^{\mathrm{F}}\left(\lambda_{\mathrm{L}}\right)$ is the fluorescence cross section for the present substance and wavelength and $\mathrm{L}^{\mathrm{F}}(\lambda)$ is the fingerprint function for the present substance.

\subsection{Ppolarization Lidar Equation}

According to equation (1), the vertical and perpendicular backscattering signal of $355 \mathrm{~nm}$ at distance $\mathrm{z}$ can be given as

$$
\begin{aligned}
& \mathrm{P}_{\perp}(\mathrm{z})=\mathrm{P}_{\mathrm{L}} \cdot \frac{\mathrm{A}_{0}}{\mathrm{z}^{2}} \cdot \xi\left(\lambda_{\mathrm{L}}\right) \cdot \beta\left(\lambda_{\mathrm{L}}, \mathrm{z}\right) \cdot \xi(\mathrm{z}) \frac{\mathrm{c}_{0} \cdot \tau_{\mathrm{L}}}{2} \cdot \mathrm{T}(\mathrm{z}) \cdot \mathrm{p}_{\perp}(\mathrm{z}) \\
& \mathrm{P}_{\|}(\mathrm{z})=\mathrm{P}_{\mathrm{L}} \cdot \frac{\mathrm{A}_{0}}{\mathrm{z}^{2}} \cdot \xi\left(\lambda_{\mathrm{L}}\right) \cdot \beta\left(\lambda_{\mathrm{L}}, \mathrm{z}\right) \cdot \xi(\mathrm{z}) \frac{\mathrm{c}_{0} \cdot \tau_{\mathrm{L}}}{2} \cdot \mathrm{T}(\mathrm{z}) \cdot \mathrm{p}_{\|}(\mathrm{z})
\end{aligned}
$$

$$
\alpha\left(\lambda_{\mathrm{L}}, \mathrm{z}\right)=\alpha_{\mathrm{atm}}\left(\lambda_{\mathrm{L}}, \mathrm{z}\right)+\alpha_{\mathrm{c}}\left(\lambda_{\mathrm{L}}, \mathrm{z}\right)
$$

The backscattering coefficient extinction coefficient $\beta\left(\lambda_{L}, z\right)$ can be also divided into two terms, one for the atmospheric background and one for the bioagents/bioaerosol cloud,

$$
\beta\left(\lambda_{\mathrm{L}}, \mathrm{z}\right)=\beta_{\mathrm{atm}}\left(\lambda_{\mathrm{L}}, \mathrm{z}\right)+\beta_{\mathrm{c}}\left(\lambda_{\mathrm{L}}, \mathrm{z}\right)
$$

The lidar ratio of atmosphere can be calculated by atmospheric mode and for the natural aerosols is set normally as $\mathrm{R}_{\mathrm{atm}}=\alpha / \beta=50$.

The fluorescence equation is similar to the lidar equation and is written as

individually and they depend on the quantum yield of PMT and optical receiving, so the depolarization ration is given as

$$
\delta(\mathrm{z})=\frac{\mathrm{P}_{\perp}(\mathrm{z}) / \mathrm{p}_{\perp}(\mathrm{z})}{\mathrm{P}_{\|}(\mathrm{z}) / \mathrm{p}_{\|}(\mathrm{z})}=\frac{\mathrm{P}_{\perp}(\mathrm{z})}{\mathrm{P}_{\|}(\mathrm{z})} \cdot \frac{\mathrm{p}_{\|}(\mathrm{z})}{\mathrm{p}_{\perp}(\mathrm{z})}
$$

Where, $K=\frac{p_{\|}(z)}{p_{\perp}(z)}$ can be obtained by experimental data.

\section{Data Retrieval for Mie Lidar}

In the hypothesis of single scattering, The Fernald method [8] was used to invert the following distributions of the aerosol extinction coefficients, the former is backward solution and the latter is forward solution.

Where, $\mathrm{p}_{\perp}(\mathrm{z})$ and $\mathrm{p}_{\|}(\mathrm{z})$ are the constant of two channel

$$
\begin{aligned}
& \alpha_{\mathrm{c}}(\mathrm{z})=-\mathrm{S} \alpha_{\mathrm{atm}}(\mathrm{z})+\frac{\mathrm{X}(\mathrm{z}) \cdot \exp \left[2(\mathrm{~S}-1) \int_{\mathrm{z}}^{\mathrm{z}_{\mathrm{c}}} \alpha_{\mathrm{atm}}\left(\mathrm{z}^{\prime}\right) \mathrm{d} \mathrm{z}^{\prime}\right]}{\frac{\mathrm{X}\left(\mathrm{z}_{\mathrm{c}}\right)}{\alpha_{\mathrm{c}}\left(\mathrm{z}_{\mathrm{c}}\right)+\mathrm{S} \alpha_{\mathrm{atm}}\left(\mathrm{z}_{\mathrm{c}}\right)}+2 \int_{\mathrm{z}}^{\mathrm{z}_{\mathrm{c}}} \mathrm{X}(\mathrm{z}) \exp \left[2(\mathrm{~S}-1) \int_{\mathrm{z}}^{\mathrm{z}_{\mathrm{c}}} \alpha_{\mathrm{atm}}\left(\mathrm{z}^{\prime \prime}\right) \mathrm{d} \mathrm{z}^{\prime \prime}\right] \mathrm{d} \mathrm{z}^{\prime}} \\
& \alpha_{\mathrm{c}}(\mathrm{z})=-\mathrm{S} \alpha_{\mathrm{atm}}(\mathrm{z})+\frac{\mathrm{X}(\mathrm{z}) \cdot \exp \left[-2(\mathrm{~S}-1) \int_{\mathrm{z}}^{\mathrm{z}_{\mathrm{c}}} \alpha_{\mathrm{atm}}\left(\mathrm{z}^{\prime}\right) \mathrm{d} \mathrm{z}^{\prime}\right]}{\frac{\mathrm{X}\left(\mathrm{z}_{\mathrm{c}}\right)}{\alpha_{\mathrm{c}}\left(\mathrm{z}_{\mathrm{c}}\right)+\mathrm{S} \alpha_{\mathrm{atm}}\left(\mathrm{z}_{\mathrm{c}}\right)}-2 \int_{\mathrm{z}}^{\mathrm{z}_{\mathrm{c}}} \mathrm{X}(\mathrm{z}) \exp \left[-2(\mathrm{~S}-1) \int_{\mathrm{z}}^{\mathrm{z}_{\mathrm{c}}} \alpha_{\mathrm{atm}}\left(\mathrm{z}^{\prime \prime}\right) \mathrm{d} \mathrm{z}^{\prime \prime}\right] \mathrm{d} \mathrm{z}^{\prime}}
\end{aligned}
$$

Where, $\mathrm{X}(\mathrm{z})=\mathrm{P}(\mathrm{z}) \cdot \mathrm{z}^{2}, S=S_{c} / S_{a t m}, S_{c}$ is the aerosol extinction-to-backscattering ratio which differs with the aerosol concentration, size distribution and chemical component, its value is chosen 40 50 suggested by Sasano and Browell [9], $S_{a t m}$ is the extinction-to-backscattering ratio of atmospheric molecular valued by $8 \pi / 3, S_{a t m}=8 \pi / 3, Z_{c}$ is calibration height which is selected by the calculation program automatically within the height range of $4.0 \sim 6.0 \mathrm{~km}$ at daytime or $6.0 \sim 8.0 \mathrm{~km}$ at nighttime. At the calibration height the content of aerosol drops to its minimized value and close to zero, so $R\left(Z_{c}\right)=\mathrm{X}\left(\mathrm{z}_{\mathrm{c}}\right) / \beta_{\mathrm{atm}}\left(\mathrm{z}_{\mathrm{c}}\right)$ comes to its minimized value. So $\alpha_{c}\left(z_{c}\right)$ can be deduced by the aerosol and atmospheric molecular scattering ratio

$$
R\left(Z_{c}\right)=\left(\left(\beta_{c}\left(\mathrm{z}_{\mathrm{c}}\right)+\beta_{a t \mathrm{~m}}\left(\mathrm{z}_{\mathrm{c}}\right) / \beta_{a t \mathrm{~m}}\left(\mathrm{z}_{\mathrm{c}}\right)\right)=1.01\right.
$$



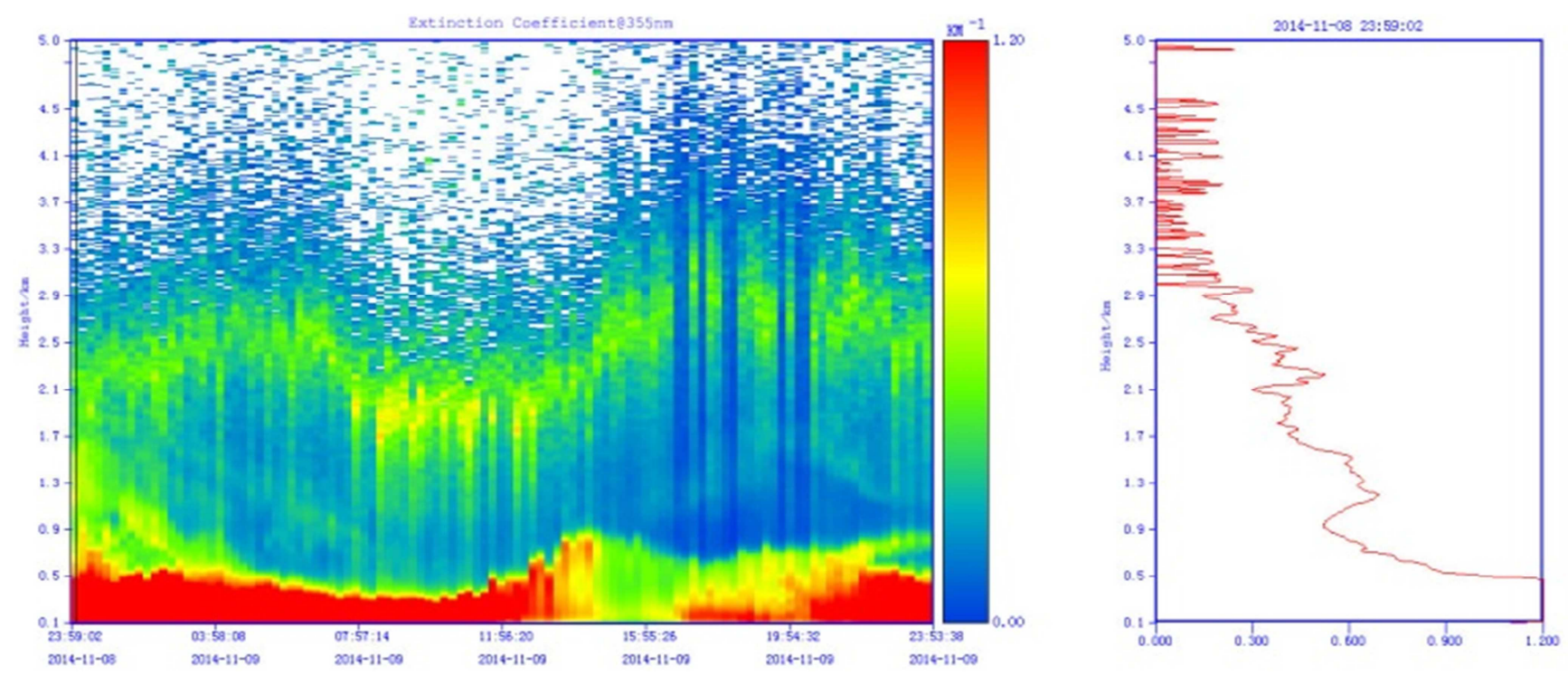

(a)
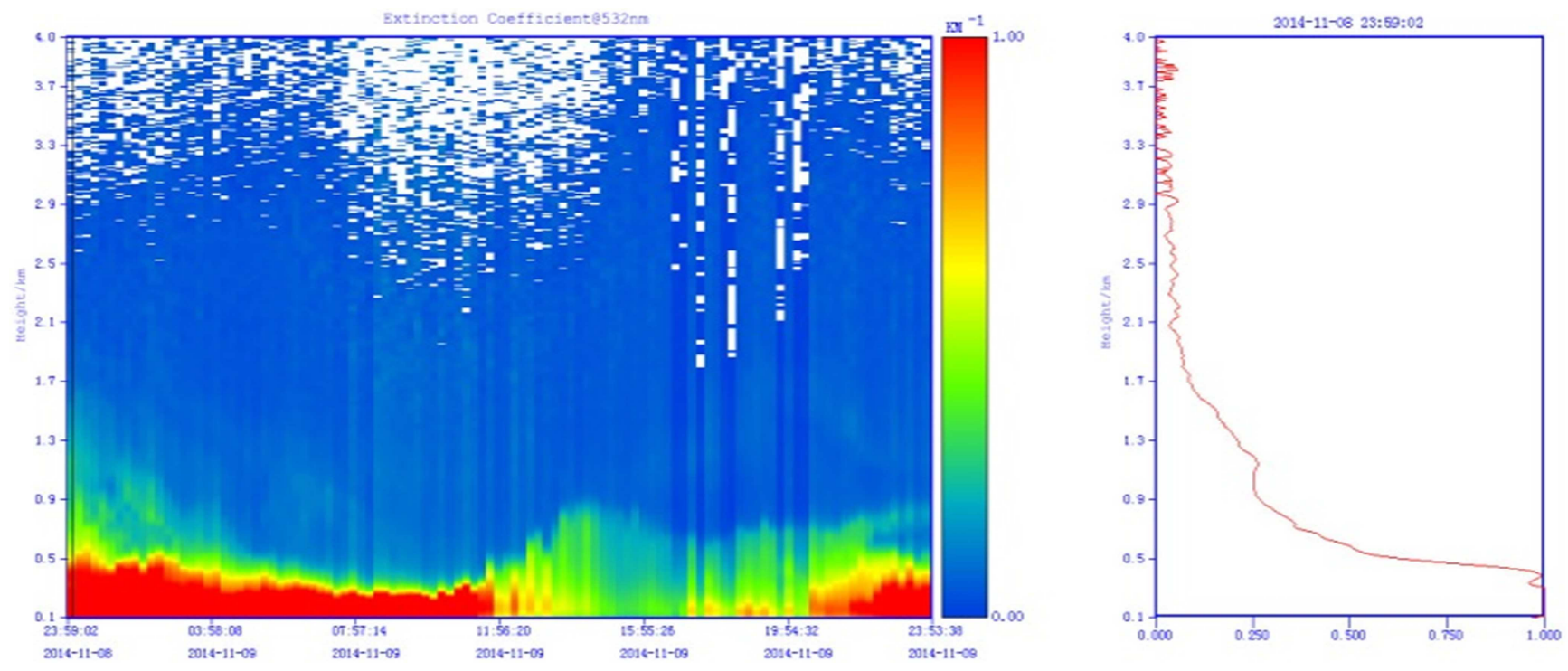

(b)

Fig. 2. Time and space distributions of bioaerosol, (a)355nm, (b)532nm.

Figure 2 shows the time and space distributions of aerosol extinction coefficient measured by our multi-channel Lidar and retrieved with the Ferald method. To the right part of each diagram shows the distribution of aerosol extinction coefficient of each laser shot. The measurements were made at hefei city, china, the lidar was laid verticallly. From figure (a) and (b), it can be easily concluded that:

At the bottom of boundary layer, the extinction coefficient distributions remained almost the same trend for the two wavelengths, the maximal value was up to $1.0 \mathrm{~km}-1$.

The extra aerosol cloud layer between heights from $1.7 \mathrm{~km}$ to $2.9 \mathrm{~km}$ were retrieved through the $355 \mathrm{~nm}$ channel, the transmittance of $532 \mathrm{~nm}$ channel is obviously higher, but $355 \mathrm{~nm}$ channel is more suitable for the fine aerosol particles monitoring with a relatively high laser energy.

\section{SNR of Fluorescence Lidar}

The SNR of fluorescence signal can be described as

$$
\operatorname{SNR}(z)=\frac{N_{s}(z)}{\sqrt{N_{s}(z)+2\left(N_{b}+N_{d}\right)}} \times \sqrt{n}
$$

Where, $N_{s}(z)$ is photo number received at height $z, N_{b}(z)$ and $N_{d}$ are the photo number of background and detector dark current respectively. The more photo number received, and less background and detector noise, the $S N R(z)$ will be higher. And also, the increased laser pulses can enhance the $S N R$. The simulated fluorescence signal and $S N R$ profiles are shown in figure 3. 


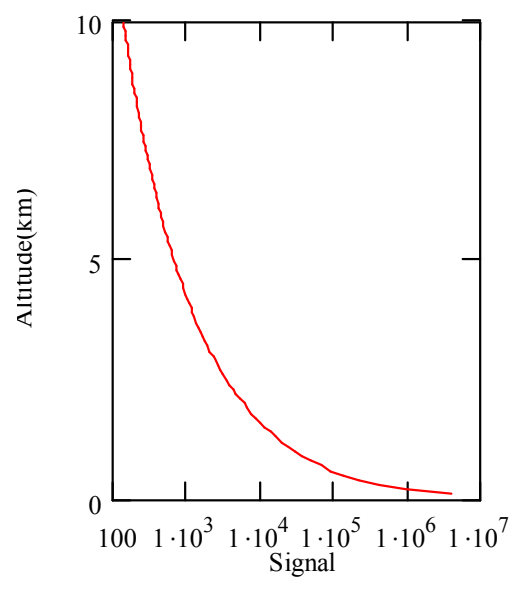

(a)

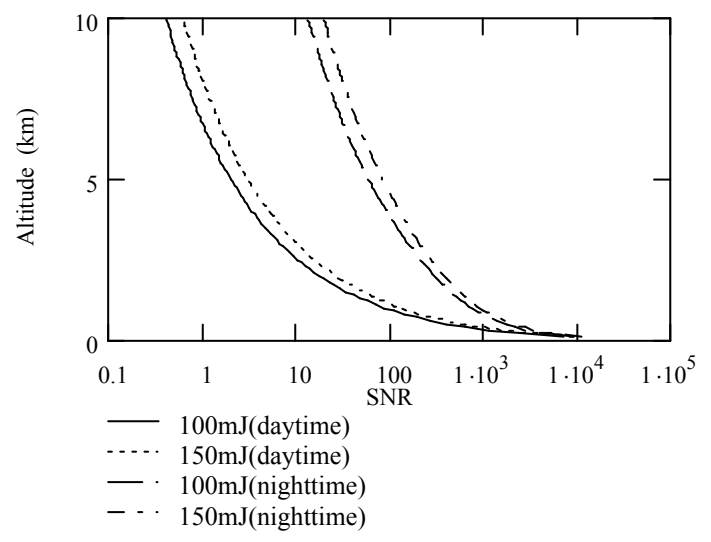

(b)

Fig. 3. Profiles of simulated fluorescence signal (a) and SNR (b).

The fluorescence signal profile was simulated with standard atmospheric mode. The number of laser pulse is set as $\mathrm{n}=2000$, the night $S N R$ is much better than that of daytime. The requirement of $S N R$ for real lidar system is set to $S N R>10$.

\section{Results of Depolarization Detection}

The time and space distributions of depolarization ratio at $355 \mathrm{~nm}$ and extinction coefficient at $532 \mathrm{~nm}$ are shown in figure 4 . The profiles were obtained by the aerosol fine particle lidar on November 27, 2014 at Hefei city. The lidar was manufactured and adjusted by AIOFM. Similarly, figure 4(a) shows the extinction coefficient profiles, and the profile at an exact single spot time is shown on the right. From figure 4, it can be shown that:

In the boundary layer, the height of $500 \mathrm{~m}$ close-ground layer decreased with the time;

In the boundary layer, the complex multi-layer structured extinction coefficient distributions were observed, it means that the aerosol concentration along the laser beam path was affected seriously by the wind, humidity, press and other atmospheric condition;

The two separated vertical distributions of depolarization ratio layer were obvious, the bottom layer is ground layer and the upper layer is surface layer and boundary layer. In the ground layer of $500 \mathrm{~m}$ height, the value of depolarization ratio remains ness than 0.01 , it means that, in this layer, the aerosol particle is in the shape of fine spherical.

After 04:00pm, in the upper surface layer and boundary layer, the zigzag structured distribution of depolarization ratio was observed clearly. At some points along the path, the maximized value of depolarization ratio reached 0.3 , it means that the height, the aerosol particle is not spherical caused by some complex physical and photochemistry processes, such as, coagulation, condensation, cohesion, and chemical reaction with the pollution materials released by the industrial and living activities, etc.
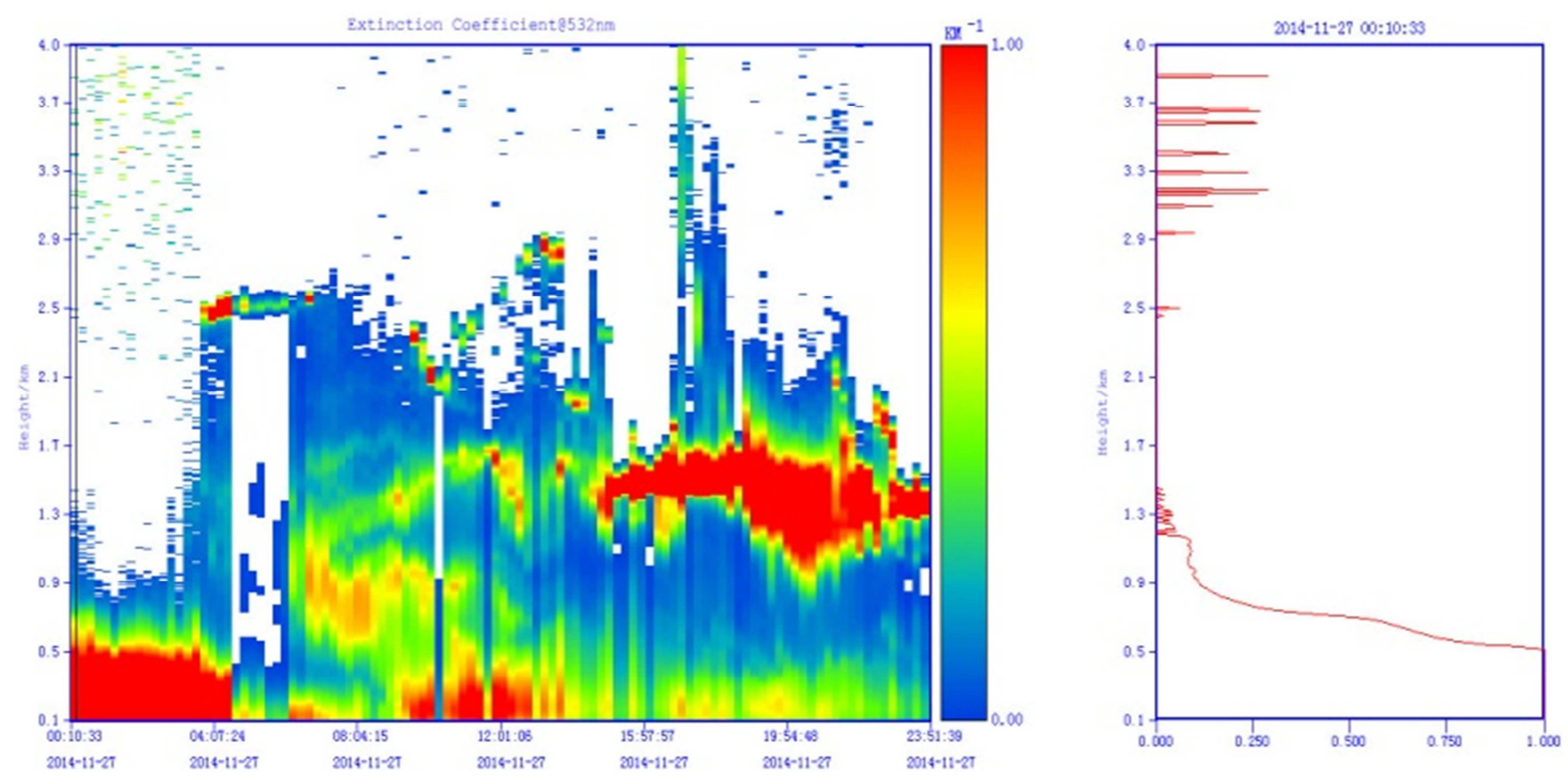

(a) 

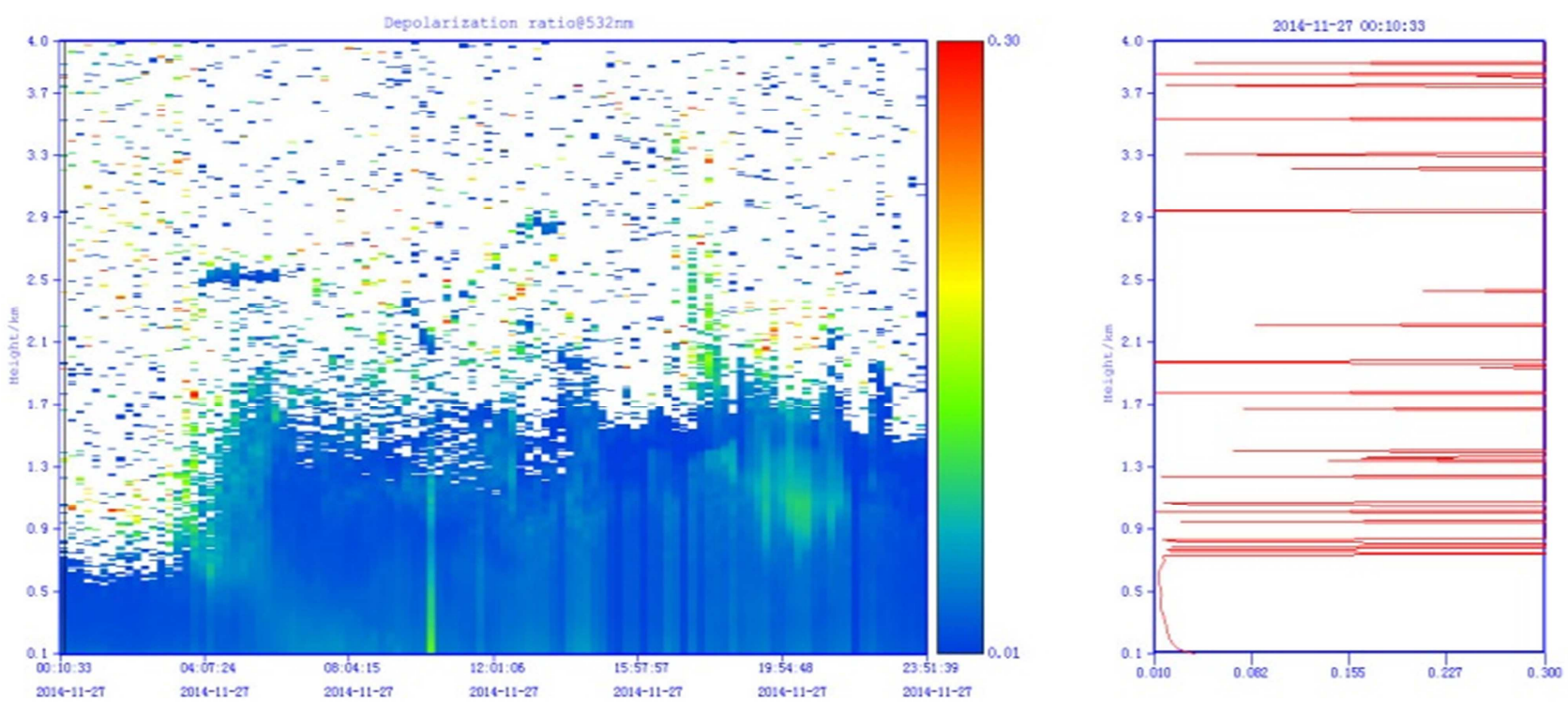

(b)

Fig. 4. Vertical and time distributions of extinction coefficient and linear depolarization ratio.

\section{Discussions and Conclusions}

The remote sensing and recognition of bioagents/bioaserosol is the hot spot in the field of photochemistry, biochemistry, etc. Scattering, fluorescence and polarization data are the effective data source of bioagents/bioaserosol time-space distribution monitoring and characteristics recognition. In this paper, the principle, data retrieve algorithms of Mie scattering, ultraviolet laser induced fluorescence lidar are introduced, and the results of vertical time-space evolvement, distributions of extinction coefficient, depolarization ratio observation were discussed.

With the combined multi-dimension observation data, the bioagents/bioaserosol recognition and discrimination appear feasible in principle. In this paper, the polarization data of $355 \mathrm{~nm}$ wavelength is discussed, and for the following next generation lidar system, polarization characteristics on more wavelengths will be measured and tested, at the same time, the PMT array will be integrated into the system for fluorescence measurement of bioaerosol or bioagents stimulants. So, future work is required to make it reality, and the following questions must be addressed: Except the time-space distribution, how to discriminate exactly bioagents/bioaserosol with observed fluorescence data? Except $355 \mathrm{~nm}$ wavelength, what wavelength is more effective for depolarization ration measurement, the shorter one or longer one? Does the depolarization ration is wavelength dependent? And what is effect of atmospheric factors, such as relative humidity, background aerosol fluctuation?

\section{Acknowledgment}

The work was supported by the National Natural Science Foundation of China named "Study on Technology of Ultraviolet Laser-induced Fluorescence LIDAR for Bioagent Remote Sensing” No. 41375026.

\section{References}

[1] Matoušek, J.; Bendík J. \& Linhart P. CBRN: biologické zbraně. CBRN "Boological weapons" Sdružení požárního a bezpečnostního inženýrství, 2007. (in Czech).

[2] Klietmann, W. F. \& Ruoff, K. "Bioterrorism: Implications for the Clinical Microbiologist", Clinical Mikrobiology Reviews, 2001, 14(2), pp. 364-81.

[3] Burger, H. A.; Solomon, W. R. "Sampling and analysis of biological aerosols". Atmospheric Enviroment, 1987, 12 (2), pp. 451-456.

[4] Health Aspects of Chemical and Biological Weapons, World Health Organization, Geneva, Switzerland, 1970.

[5] D. R. Walt and D. R. Franz, "Biological Warfare Detection", Analytical Cemistry, pp. 378 A-746 A, 2000.

[6] G. M. Dougherty, D. S. Clague, and R. R. Miles, B. Fieldcapable biodetection devices for homeland security missions. SPIE Opt. Photon. Global Homeland Security III, vol. 6540, 2007.

[7] Measures, R. M., Laser Remote Sensing: Fundamentals and Applications, John Wiley \& Sons, New York, 1984.

[8] Fernald, F. G., Analysis of atmospheric lidar observation: some comments, Appl. Opt., 1984; 23, pp. 652 655.

[9] Y. Sasano and E. V. Browell, Light scattering characteristics of various aerosol types derived from multiple wavelength lidar observations, Appl. Opt. 1989, 28, pp. 1670 1679.

[10] Xiaoying Cao, Gilles Roy and Robert Bernier, Lidar polarization discrimination of bioaerosols, Optical Engineering, 2010, 49(11), pp. 116201-1 116201-12.

[11] Nianwen Cao, Cunxiong Zhu, Shaobo Yang, Yinhai Xie, Fengkai Yang, and Feng Zhang, Identification of Aerosol Species Using Polarization Lidar, Optics and Spectroscopy, 2014, 117( 3), pp. 486-491. 